\title{
Study on Preparation and Properties of U3160/3266 Composites by Ex-situ Toughening Method
}

\author{
Li Yan ${ }^{1, a}$, Xuefeng $A n^{1, b}$ \\ ${ }^{1}$ National Key Laboratory of Advanced Composites, Beijing Institute of Aeronautical Materials, AVIC \\ Composites Technology Center, Beijing 100095, China \\ ayanli0827@163.com, banxuefeng@gmail.com,
}

Keywords: Ex-situ toughening; composites; interlaminar fracture toughness; low-velocity impact damage; polyethersulphone

Abstract. The ES-U3160 reinforced fabrics with toughening function were prepared by adhering the Ex-situ elasticizer polyethersulphone homogeneously on reinforced fabrics according to Ex-situ toughening technology. Composites were prepared by RTM process taking U3160 and ES-U3160 fabrics as reinforcement. The toughness properties of U3160/3266 composites by Ex-situ toughening were investigated through interlaminar fracture toughness test and low-velocity impact test. The results showed that compared with U3160/3266 composites, ES-U3160/3266 composites had higher $\mathrm{G}_{\text {IC }}$ value, $\mathrm{G}_{\text {IIC }}$ value and CAI value. Based on Ex-situ toughening concept, the thermoplastic/thermosetting co-continuous phase was formed, which dramatically improved the interlaminar fracture toughness, impact damage resistance and impact damage tolerance.

\section{Introduction}

Composites offer an attractive potential for reducing the weight of high-performance structures as consequences of their high specific strength and stiffness. Although these materials offer excellent in-plane performance they have inferior through-thickness properties and in case of impact loads, the damage resultant can range from matrix cracking, fibre failure and/or delaminations [1-5].With the wide application of composites, improving toughness of composites has been always a focus of domestic and foreign concern.

The Resin Transfer Molding(RTM) process has been widely used in various industries because products can be manufactured easily and the cost for manufacturing is lower than that of other manufacturing methods [6-7]. But it's a great challenge for RTM technology to keep the processing while improving toughness of composites. Traditional toughness method was to blend thermoplastics into a matrix resin by dispersion or dissolving, but the integral toughness method had greatly increased viscosity of resin and decreased flow of resin, seriously affected RTM processing. However, Ex-situ toughening technology [8-14] proposed by Xiaosu Yi can effectively solve the contradiction between low viscosity of resin and high toughness of composites during RTM process and significantly improve interlayer performance. ES-fabrics were prepared by adhering the Ex-situ elasticizer polyethersulphone homogeneously on reinforced fabrics according to Ex-situ toughening technology. And ES-Fabrics with toughed function have been prepared highly efficiently and stably by coating equipment independently developed [15-17].

In this article, the ES-U3160 reinforced fabrics with toughening function were prepared by adhering the Ex-situ elasticizer polyethersulphone (PES) homogeneously on reinforced fabrics. ES-U3160/3266 CF reinforced epoxy resin matrix composites were prepared by RTM process taking ES- Fabric reinforced fabrics as reinforcement. Compared with U3160/3266 nontoughening composites, the interlaminar fracture toughness and the impact properties of ES-U3160/3266 and toughening mechanism was studied.

\section{Experimental details}

Mateials. Epoxy resin(3266) is a product of Beijing Institute of Aeronautical Materials (BIAM), which is an aerospace-grade epoxy commercialized. U3160 unidirectional textile with an areal density of $160 \mathrm{~g} / \mathrm{m}^{2}$ was 
purchased from Weihai development Fiber Co., Ltd. Polyethersulphone (PES) with the model of VW-10200RFP was purchased from American Solvay company.

Preparation of U3160/3266 composites. ES-U3160 fabrics were prepared by coating equipment independently developed, which could realize the high quality, high efficiency and stabilization of preparation of ES-U3160 fabrics. Composites were prepared by resin transfer molding (RTM) process taking U3160 and ES-U3160 fabrics as reinforcement. The quasi-isotropic composites for CAI testing with ply of [45/0/-45/90] $]_{4 \mathrm{~s}}$ were prepared. The ply of samples for mode I and mod II interlaminar fracture toughness testing was $[0]_{20}$ and $[0]_{24}$ respectively. Fiber volume fraction was $56 \% \pm 2 \%$.

Properties testing and morphology analysis. The impact testing of laminates was determined follwing the standard of ASTM 7136-05 on a drop-weight impact testing machine (INSTRON 9250HV). The drop-weight testing machine consisted of a drop tower equipped with an impactor, which had high bandwidth digital signal processing (DSP) electronics, impulse TM control and data acquisition software.The impact energy was $6.67 \mathrm{~J} / \mathrm{mm}$. And then all the specimens were subjected to compression strength testing to determine their compression-after-impact (CAI) characteristics and strength. Mode I and mod II interlaminar fracture toughness testing were tested following the standard of ASTM D 5528 and HB 7043 respectively. Interlayer morphology of composite laminates was observed by SEM.

\section{Results and discussion}

Interlaminar fracture toughness testing. The fracture toughness was the index of the ability of the crack propagation. The smaller the value was, the more easily the interlayer crack was extened. As shown in Fig. 1, the $\mathrm{G}_{\mathrm{IC}}$ value and $\mathrm{G}_{\text {IIC }}$ value of $\mathrm{U} 3160 / 3266$ composites were $345 \mathrm{~J} / \mathrm{m}^{2}$ and $1057 \mathrm{~J} / \mathrm{m}^{2}$ respectively. The $\mathrm{G}_{\mathrm{IC}}$ value and $\mathrm{G}_{\text {IIC }}$ value of ES-U3160/3266 composites toughened by polyethersulphone increased by $80 \%$, compared with that of non tougheningcomposites.

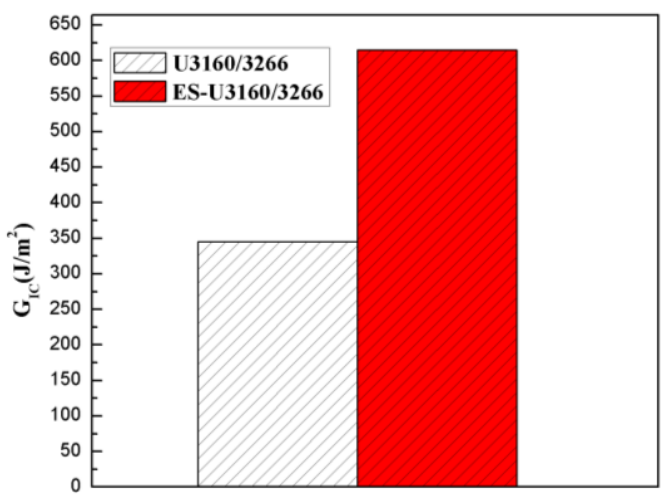

(a) $\mathrm{G}_{\mathrm{IC}}$

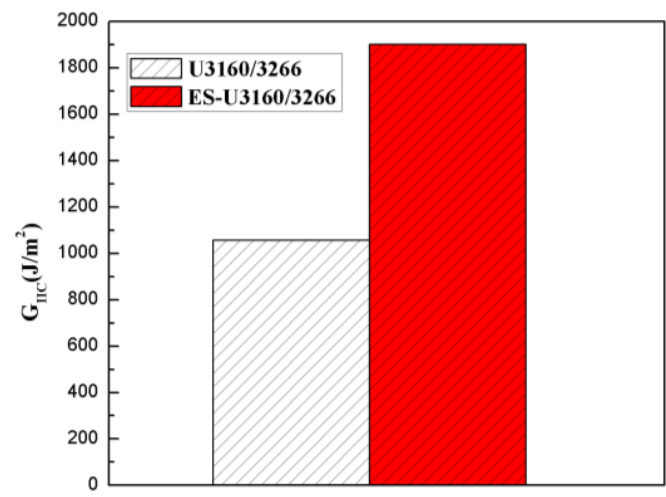

(b) $\mathrm{G}_{\text {IIC }}$

Fig. 1 The interlaminar fracture tougheness of 3266 epoxy matrix composies

Fig. 2 showed SEM images of fracture surface from crack initial region of U3160/3266 and ES-U3160/3266 composites after mode I test. As seen from Fig. 2, the interface between the resin and the fiber was strong, resin fracture was the main failure mode for U3160/3266 composites (Fig. 2(a)) and fracture surface appeared tortuous ridge river patterns. This was a feature of ductile fracture of brittle laminates. For ES-U3160/3266 composites by Ex-situ toughening method (Fig. 2(b)), the structure of thermoplastic/thermosetting co-continuous phase was formed. The continuous phase of the rich epoxy thermosetting particles dispersed in the thermoplastic PES. The destruction of the structure of the fracture of the thermoplastic PES phase and debonding of thermosetting particles could absorb a lot of energy. 


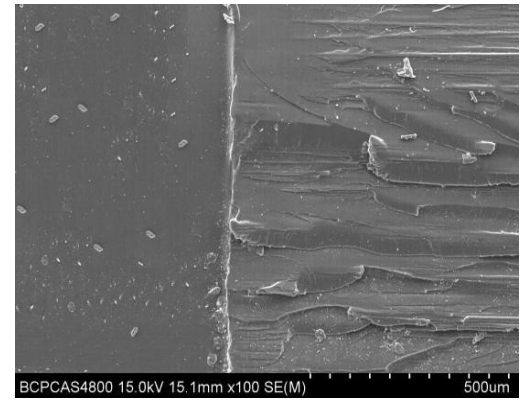

(a) $\mathrm{U} 3160 / 3266$

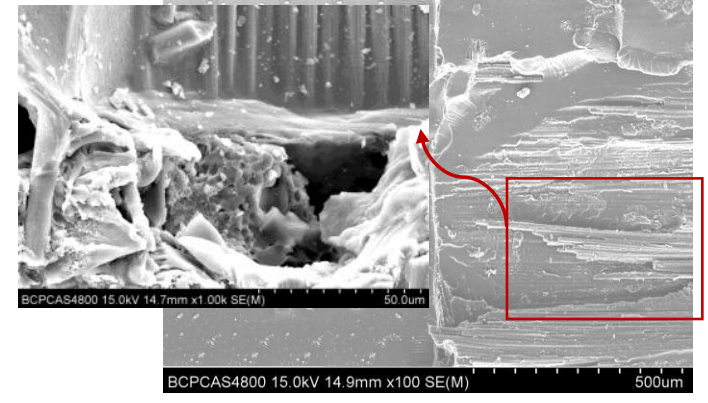

(b) ES-U3160/3266

Fig. 2 SEM images of fracture surface from crack initial region of composites after mode I test

Fig. 3 showed SEM images of fracture surface from crack propagated region of U3160/3266 and ES-U3160/3266 composites after mode I test. For U3160/3266 composites Fig. 3(a), resin fracture was still the main failure mode. In addition, the interface failure of fiber/resin and fiber breakage was also observed from Fig. 3(a). However, as shown in Fig. 3(b), for ES-U3160/3266 composites, phase seperation and phase inversion occured in the layer. The crack propagation in the sample layer was covered with epoxy resin particles, which blocked the crack growth. Plastic deformation of thermoplastic PES in continuous epoxy resin particles absorbed the energy of the interlayer opening. Under the condition of large tensile force, the shrinkage force of the PES thin layer pressed on the epoxy resin particles and then synergistic effect of PES thin layer with resin particles appeared. Once the crack was initiated, the stress state was degenerated into a simple tension. At this time, the cohesive of PES was greater than that of interfacial adhesion force between epoxy resin particles and PES particles. And the plastic deformation of PES played a major part in the course of crack propagation. Synergistic effect of PES thin layer with epoxy resin particles provided the crack initiation resistance and crack opening resistance of the specimen, and provided higher $\mathrm{G}_{\mathrm{IC}}$ value. So the unique structure of the rigid particles and the ductile particles was the basic reason for high toughness of composites.

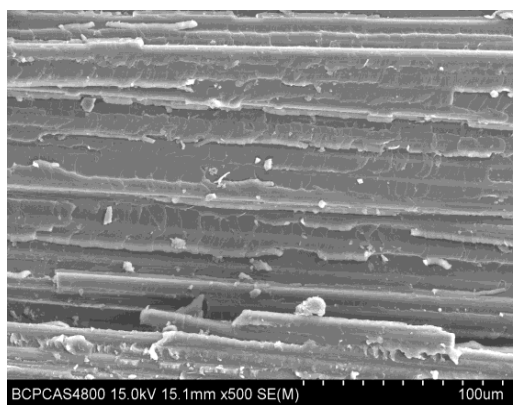

(a)U3160/3266

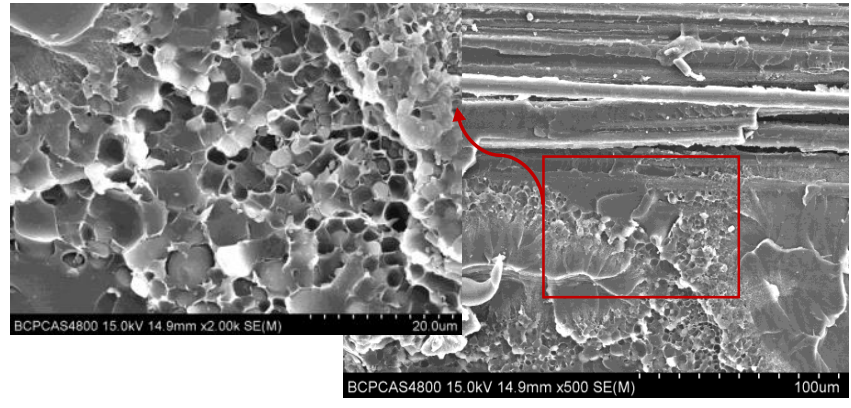

(b) ES-U3160/3266

Fig. 3 SEM images of fracture surface from crack propagated region of composites after mode I test

SEM images of fracture surface of U3160/3266 and ES-U3160/3266 composites after mode II test was found from Fig. 4. As indicated in Fig. 4(a), for U3160/3266 composites, there was a large number of bare fiber on the fracture surface and only part of the fiber was coated by highly deformed resin. In Fig. 4(b), the fracture surface of ES-U3160/3266 composites had been more rough. And the deformation and fracture of the thermoplastic PES and the void left by the rich epoxy resin phase appeared on the fracture surface. Ductile resin increased the plastic yield zone size of the crack tip, which was more conductive to load redistribution. And further energy was absorbed by kinds of toughnening mechanism. 

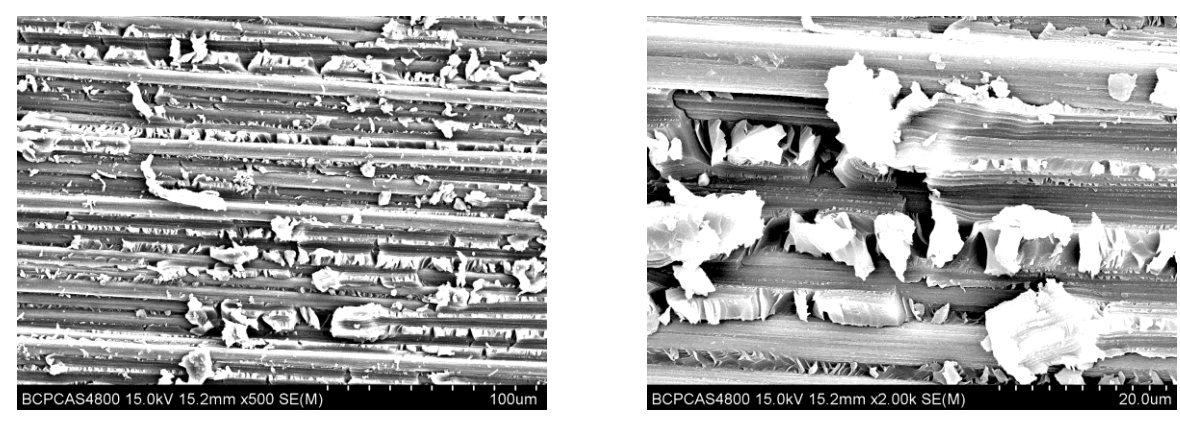

(a) $\mathrm{U} 3160 / 3266$
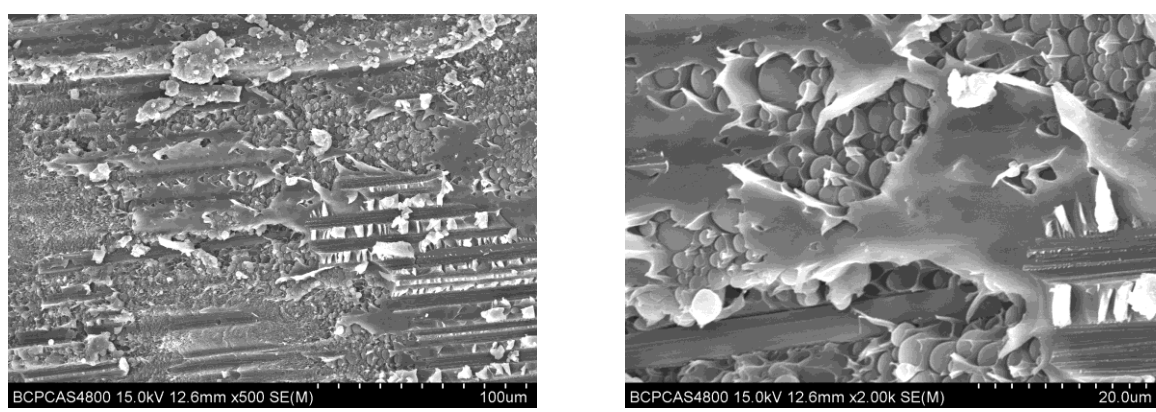

(b) ES-U3160/3266

Fig. 4 SEM images of fracture surface of composites after mode II test

Low velocity impact testing. Fig. 5 showed impact force histories for U3160/3266 and ES-U3160/3266 composite laminates under the impact energy $6.67 \mathrm{~J} / \mathrm{mm}$. As seen from Fig. 5(a), for U3160/3266 composites, when the contact time was $0.64 \mathrm{~ms}$, the load hade been severely reduced. This was related to the stucture delamination damage of composites laminates and the damage threshold (DTL) appearing was 8360 N. For ES-U3160/3266 composites, the load decreased at a later time, but the reduction was small and DTL value was $9600 \mathrm{~N}$. From the graph, we could conclude that the delamination onset load and the maximum load of ES-U3160/3266 toughening composites were higher than U3160/3266 non toughening composites. This was due to the plastic deformation of interlayer elasticizer which improved impact resistance ability. As shown in Fig. 5(b), compared with U3160/3266 composites, the displament of DTL value of ES-U3160/3266 composites was larger and then the fluctuation of the curve was smaller. The toughening layer could effectively retard the crack growth and the crack was propagated in a more stable way.

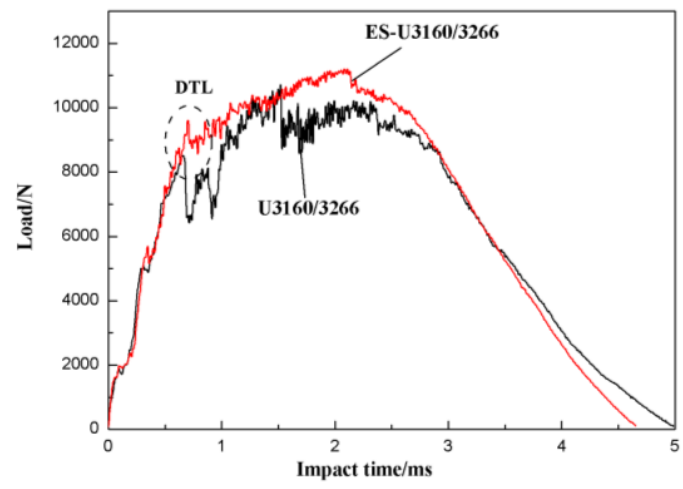

(a) Load-impact time curves

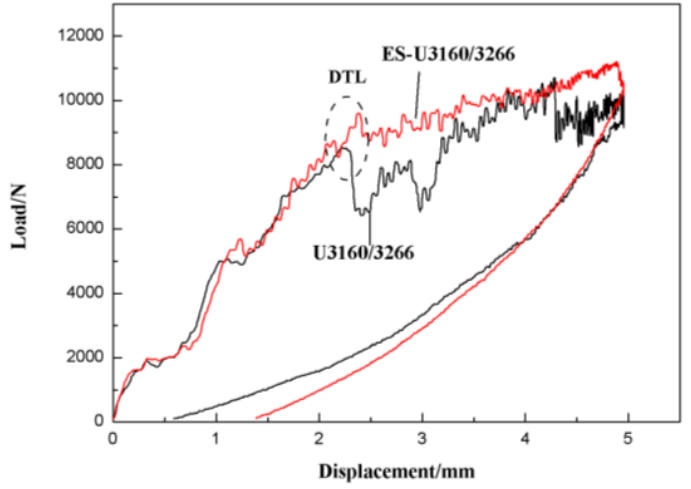

(b) Load-displacement curves

Fig. 5 Load-impact time curves and load-displacement curves in the process of impact tesing

As shown in Fig. 6, CAI value of ES-U3160/3266 composites toughened by polyethersulphone increased by $30 \%$, compared with that of non tougheningcomposites. As seen from C-scan, the damage area of the ES-U3160/3266 toughening laminate was that of the U3160/3266 non toughening laminate 1/2. Ex-situ 
toughening could inhibit the internal damage extension of ES-U3160/3266 composite laminates. So under the same impact energy, the toughening laminates had not only small damage area, but also the compression strength of the laminates were significantly improved than the non toughening laminates.

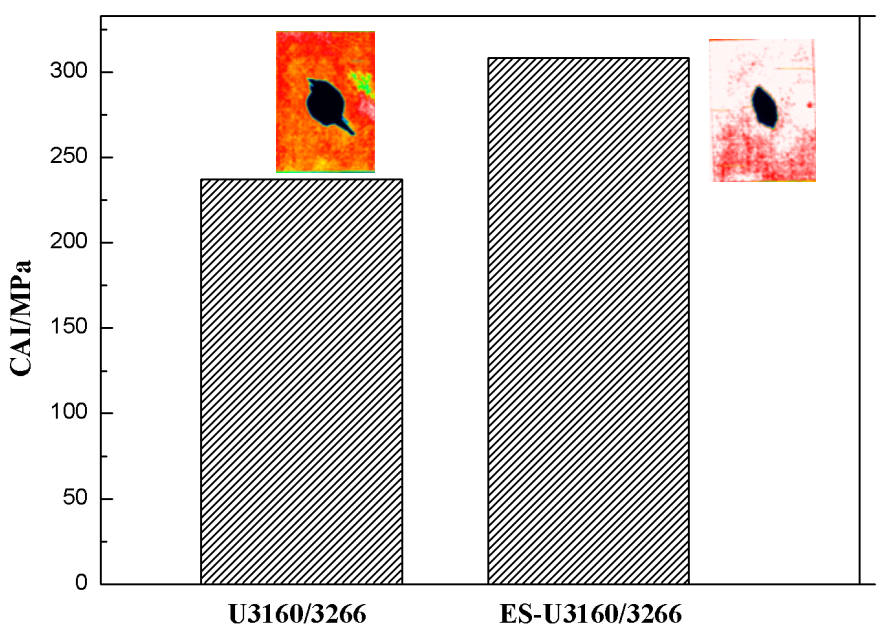

Fig. 6 The CAI value and C-scan photos of 3266 epoxy matrix composites

\section{Conclusions}

Following conclusions were drawn from this work:

(1) Compared with U3160/3266 composites, ES-U3160/3266 composites had higher $\mathrm{G}_{\text {IC }}$ value and $\mathrm{G}_{\text {IIC }}$ value.

(2) Based on Ex-situ toughening concept, the thermoplastic/thermosetting co-continuous phase was formed. The plastic deformation of PES played a major part in the course of crack propagation. This structure was the main reason for improving the toughness of composites dramatically.

(3) Composites based on Ex-situ toughening concept not only improved impact damage resistance (appraised by the shadow area of delamination C-scan), also improved compression after impact (appraised by CAI value). Toughening effect of ES-U3160/3266 composites by Ex-situ toughening method was obvious. ES-U3160/3266 composites had a smaller area of delamination damage and higher CAI value.

\section{References}

[1] Abrate S. Impact on laminated composite materials. Appl Mech Rev 1991;44:155-90.

[2] Cantwell WJ, Morton J. Comparison of the low and high velocity impact response of CFRP. Composites 1989, 20:545-551.

[3] de Moura MFSF, Marques AT. Prediction of low velocity impact damage in carbon-epoxy laminates. Compos Part A, 2002, 33:361-368.

[4] Amaro AM, de Moura MFSF, Reis PNB. Residual strength after low velocity impact in carbon-epoxy laminates. Mater Sci Forum 2006: 514-516.

[5] Amaro AM, Reis PNB, de Moura MFSF. Delamination effect on bending behaviour in carbon-epoxy composites. Strain 2011, 47: 203-208.

[6] Mallick PK. Proceedings of the twelfth US-Japan conference on composite materials. USA: DEStech Publications; 2006.

[7] Lee GW, Lee NG, Janga J, Lee KJ, Nam JD. Effects of surface modification on the resin-transfer moulding (RTM) of glass-fibre/unsaturated-polyester composites. Compos Sci Technol 2002;62:9-16. 
[8] An X F, Tang B M, YiX S, et a1. Toughness improvement of carbon laminates by periodic interleaving thin films [J]. Journal of Materials Science Letters, 2002, 21(22): 1763-1765.

[9] Yi X S, An X F, Tang B M, et a1. Ex-situ formation of periodic interlayer structure to improve significantly the impact damage resistance of carbon laminates [J]. Advance Engineering Materials, 2003, 5(10): 729-732.

[10] Long W, Xu Y H, YiX S, et al. Preliminary study on resin transfer molding of highly-toughened graphite laminates by Ex-situ method [J]. Journal of Materials Science, 2004, 39(6): 2263-2266.

[11] Cheng Q F, Fang Z P, Xu Y H, et al. Improvement of the impact damage resistance of BMI/graphite laminates by the Ex-situ method [J]. High Performance Polymers, 2006, 18(6): 907-917.

[12] Cheng Q F, Fang Z P, Yi X S, et al. Ex-situ concept for toughening the RTM able BMI matrix composites I: Improving the interlaminar fracture toughness [J]. Journal of Applied Polymer Science, 2008, 109(3): 1625-1634.

[13] Cheng Q F, Fang Z P, Yi X S, et al. Ex-situ concept for toughening the RTM able BMI matrix composites II: Improving the compression after impact [J]. Journal of Applied Polymer Science, 2008, 108(4): 2211-2217.

[14] Cheng Q F, Fang ZP, Xu Y H, et al. Morphological and spatial effects on toughness and impact damage resistance of PAEK-toughened BMI and graphite fiber composite laminates [J], Chinese Journal of Aeronautics, 2009, 22(1): 87-96.

[15 An X F, Li H Y, Yi X S. ES-Fabric with function of elasticizer and stereotyper and its manufacturing technology [J], Aeronautical Manufacturing Technology, 2008, 15: 90-91.

[16] Yan L, An X F, DONG H M, et al. Preparation and properties of Cf/BMI composites modified by polythersulphone[J], Aerospace Materials and technology, 2014, 44(4): 36-39.

[17] Yan L, An XF. Preparation and Impact properties of ES-U3160/5284 composites by RTM process[J], Advances in Engineering Research, 2015, 27: 2207-2211. 